\title{
Outside: Extreme Environments and Creative Resistance
}

\section{GEORGE ELVIN}

Ball State University
As global climate change pushes local climates to new extremes, a new and important question is being asked: What can we learn from today's most extreme environments which can help us adapt to a rapidly changing climate? Answering it may produce valuable lessons for adapting to climate change, but it also begs new questions about how [ital] or even if [ital] we should be mining extreme environments for resilient design knowledge. As these unique and fragile environments more frequently become the subject of research and teaching, what are the implications for the people who call them home? Does increased trafficking in the resulting knowledge represent exploitation or cultural appropriation? Does discourse built on that knowledge exclude indigenous and aboriginal people? This paper explores the impacts of mining extreme environments for resilient design knowledge on the indigenous and aboriginal knowledge bearers. It seeks to identify relationships between agents in that knowledge exchange and the discourse it fuels. These agents include indigenous and aboriginal knowledge bearers as well as knowledge seekers and consumers in the majority culture. And it places these relationships within broader contexts of culture, environment, society, commerce and theory.

\section{INDIGENOUS KNOWLEDGE AND RESILIENT DESIGN}

Mining extreme environments for resilient design knowledge is one response to an urgent and unprecedented problem: global climate change. It proposes that, as local climates become more extreme as a result of global climate change, we should study today's most extreme environments for lessons in adaptive living. It assumes that these environments hold secrets in adaptive living because both humans and animals have adapted to them. These secrets may then be applied in the resilient design of buildings, artifacts, and behaviors enabling residents of more benign environments to adapt to changes as their local climates become more extreme.

While the practice of mining extreme environments for resilient design knowledge is relatively new, it may employ methods of knowledge capture similar to those used in applied ethnography and human ecology. The applied aspect of this is significant, since investigators are not simply trying to understand an environment or its inhabitants. Rather, they are probing each for answers to a specific question: "What lessons does this person or place hold that can help others adapt to climate extremes?" The inquiry seems reasonable at face value-the study of extreme ecosystems may help us to

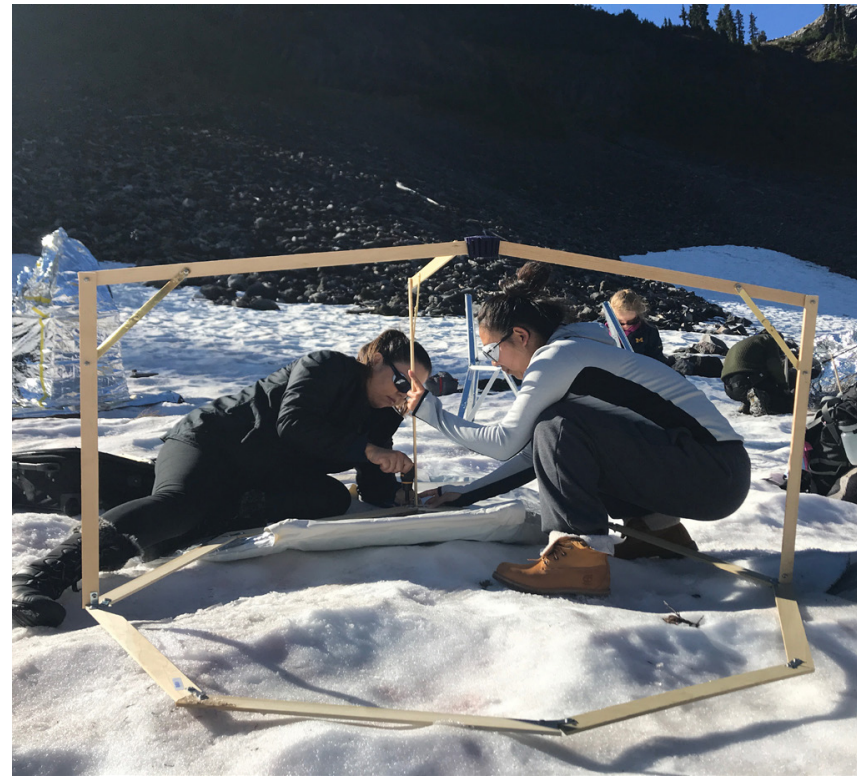

Figure 1. The author's students explore extreme environments in the Cascade Mountain Range to learn nature's lessons in resilient design.

prepare for future extremes in less hostile ones. Indigenous or vernacular architecture adapted to local extremes over hundreds or thousands of years should offer lessons for similar adaptations elsewhere, as may the knowledge of local people.

But a closer look behind the façade of these seemingly benign questions is in order. The history of ethnography is rife with examples of well-intentioned investigators asking innocent questions of their subjects. The act of studying people, even by observation alone, may alter them and their cultures. The extraction of local knowledge raises serious questions of cultural appropriation and exploitation, particularly when the inquisitor represents a dominant culture and the respondent a dominated one. Indigenous and aboriginal knowledge extracted from extreme environments is a critical building block in environmental discourse. But does this discourse exclude the very people whose knowledge it is built on?

\section{CULTURAL APPROPRIATION}

In addition to studying ecosystems in extreme environments for resilient design knowledge, researchers may study local people to gain knowledge. These are often indigenous or aboriginal people in minority cultures who have been marginalized to their extreme environments by a majority culture. 
And yet, according to the Intergovernmental Panel on Climate Change Working Group, "Indigenous, local, and traditional knowledge systems and practices, including indigenous peoples' holistic view of community and environment, are a major resource for adapting to climate change ..."1 Yankton Sioux activist Faith Spotted Eagle, however, reminds us that, "When you think about it from our perspective, this sacred site knowledge that we have, knowledge is property." If indigenous knowledge is to be appropriated by other cultures to mitigate climate change, the issue of cultural appropriation must be addressed.

Cultural appropriation occurs when traditional knowledge results in capital gain by an outside agent without recompense to its originators. A frequently cited example is biopiracy-the commercialization of biological or genetic material, (medicinal plants, for example,) without compensating its originators. To paraphrase Celia Haig-Brown, what happens when outsiders appropriate culturally-based concepts, beliefs, values, and thought processes for purposes other than what may have initially been intended by the originators? ${ }^{3}$ Haig-Brown cites Peter Shand's use of the term, modernist affinity, to answer this question. Modernist affinity, according to Haig-Brown, "affects a dislocation of the source form from its initial cultural context. In so doing, specific meanings are erased and cultural significances shift and slide to the point that some have argued the appropriation to be an equivalent of colonial occupation of indigenous art and design ..." The analogy of colonial occupation may be even more fitting when we consider the appropriation of space, not in the sense of physical occupation, but in the appropriation of the minority concept [ital] of space. To take just one example, majority environmental discourse on the space of extreme environments occupied by indigenous people is unlikely to include the role of spirits, which may be central to minority environmental discourse.

The appropriation and capitalization of minority knowledge can affect minority people in a variety of ways. The Native American teepee, for example, is in many ways better adapted to environmental extremes than the typical suburban house. Could the appropriation of this cultural icon by a dominant culture offend in the same way as the Washington Redskins name and mascot? Is the "borrowing" of another culture's knowledge and design principles or practices unethical, especially when the capital reality is that these things are not borrowed, but often taken outright and sold? What are the rights of the seller or subject of study in these cases?

Even when there is agreement that minority cultures need to be compensated for the use of their knowledge, complications arise. For instance, cultures [ital] cannot receive compensation. In an effort to address the question of distribution of compensation within a culture, the Zuni tribe, for example, established its own publishing house. Even then, complexities remained, as divergent worldviews came into play. Former Zuni publications director, Anne Beckett, explained that, "the square peg of Zuni tradition and philosophy is trying to place itself in the round hole of Western intellectual property. Zuni tradition is predicated upon collective rights, and intellectual property is based on individual rights never conceived of by Zunis."

"Zuni traditions are collectively owned in ways never conceived of by laws," she added. "In forcing people to adapt to Western ways we are in the process of destroying something ancient and irreplaceable." And, "We must temper our [majority culture] fascination with the need to know. We really don't need to know everything about everybody. Somewhere along the line our curiosity got lethal."4

\section{ENVIRONMENTAL DISCOURSE}

While our curiosity may be considered lethal to indigenous or aboriginal cultures by some, others may consider it necessary for our survival. Members of the Intergovernmental Panel on Climate Change Working Group are not the only ones targeting indigenous peoples' knowledge as a major resource for adapting to climate change, and the thirst for knowledge which can be applied to resilient design and climate adaption is unlikely to abate. If the effects of climate change continue to increase, so will the quest for adaptive architectural solutions. Cultural appropriation which excludes indigenous knowledge providers from the rewards of capitalization of the knowledge appropriated is just one possible consequence of this quest. But there are other types of rewards at risk as well. In the academic realm which values the theoretical capital of papers, books and courses, discourse [ital] may be even more important. To understand all the effects of knowledge mining on indigenous and aboriginal knowledge-bearing cultures, we must consider the discourse built on that knowledge.

Environmental discourse is a complex system, to be sure, with a variety of agents interacting in multiple relationships and contexts. Agents include the initiators of the knowledge exchange. In extreme environments these are typically outside agents seeking knowledge-researchers, teachers and, perhaps, businesses or governmental authorities. These researchers may seek knowledge directly from the environment, as when a biologist studies an extreme ecosystem. But knowledge exchange becomes more complex when they seek knowledge from the environment's inhabitants. Researchers, however, are not the ultimate consumers of the knowledge appropriated from these knowledge bearers. Rather, they transform what they learn into capital, as when the biologist publishes a paper on her findings. The ultimate consumer in this case is the audience of the paper and other research products.

These make up the three critical players in the extreme environment knowledge mining system: knowledge seeker 


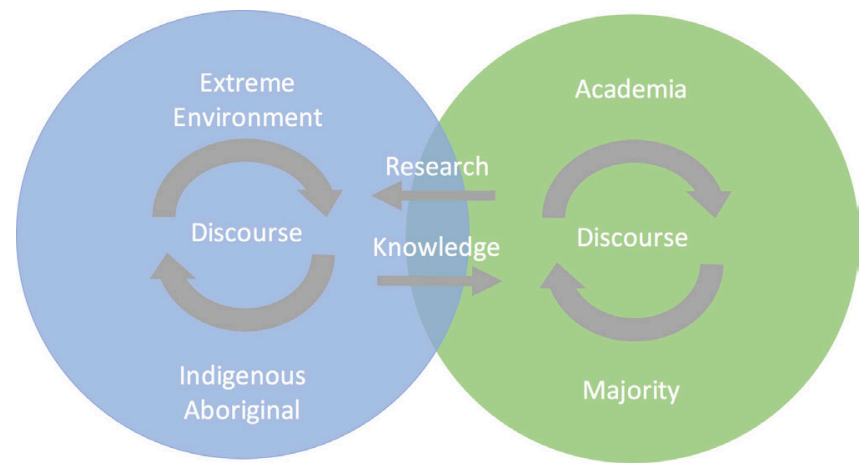

Figure 2. Agents and relationships in knowledge mining in extreme environments.

(or researcher), knowledge bearer, and knowledge consumer. Teaching scenarios are close enough in character to research scenarios that they may be included in this model. Commercial and governmental scenarios may fall outside its scope. Relationships between these three types of agents are the seeker-bearer relationship, the seeker-consumer relationship, and the bearer-consumer relationship. Relationships between knowledge seekers and knowledge bearers in extreme environments typically take the form of an exchange of capital, one-sided as it may sometimes be. These relationships and exchanges take place within multiple contexts theoretical, cultural, social, commercial and environmental.

\section{INDIGENOUS KNOWLEDGE IN ENVIRONMENTAL METADISCOURSE}

Architectural research and education constitute a relatively well-defined body of knowledge. Researchers seek to add to that body of knowledge with new discoveries and ideas in the field of resilient design. Extreme environments are ideal locations for discovering such knowledge because their ecosystems and inhabitants have evolved many adaptive strategies. But the theoretical context of research and education extends well beyond the realm of resilient design. Because minority, and often indigenous or aboriginal, peoples are frequently marginalized to the most extreme environments, it is often their knowledge that is mined for lessons in resilient design. This extends the theoretical context of the search for resilient design knowledge to include the theoretical world of the minority culture. The entire world of indigenous or aboriginal beliefs, thought processes, epistemologies and ontologies may come into play.

The theoretical context of the researcher is also engaged. This may include academic discourse, science, philosophy, and a host of other theoretical issues. Also, as publication and dissemination are critical parts of the research process, the theoretical world of the consumer-the audience of the research publications-becomes part of the context. And while this audience is typically other researchers, knowledge of extreme environments may also be brought back to the classroom. This brings in the theoretical context of the students, which may differ greatly from that of the instructor. In sum, the primary theoretical contexts engaged in architectural research and education on extreme environments are not only those of the knowledge seeker and the knowledge bearer, but also those of the audience or end users such as readers and students.

While research and knowledge on extreme environments should, in principle, be grounded in direct experience of those environments, discourse itself may come to self-define not only content but participation. Because discourse "puts forward certain concepts, viewpoints and values at the expense of others," it may include or exclude, empower or disempower certain ideas, worldviews and individuals. The differing concepts, viewpoints and values of minority and majority agents may result in mutual exclusion. Non-minority researchers may be excluded from minority discourse on extreme environments, and minority researchers may be excluded from academic discourse on them, or have to choose an identity within or outside their culture. Inclusion and exclusion in discourse may have consequences for academic or social status as well as financial rewards, as Khristaan D. Villela reminds us by noting, "We live in a world in which Native, minority, and often post-colonial peoples still struggle to regain or establish agency."

Publications, conference presentations and classroom teaching about the environment shape culture-wide discourse on the environment. Some argue that our perceptions of the environment are shaped more by our discourse on it than by our direct experience of it. ${ }^{7}$ In this way, discourse and culture may be seen as the mechanisms by which, "The environment itself is a human construction rather than an a priori [ital "a priori"] condition."8

For example, my own experience on Hawaii's Mt. Wai'ale'ale, the second wettest place on earth, contributed to, among other objects of discourse, this article. Given the mountain's isolation, it is unlikely that readers would have direct experience of this place; their understanding of it would be shaped by my interpretation or misinterpretation of it. This disengagement of discourse from experience would be of little consequence if I were simply describing the scenery. But since academic discourse is about ideas, my contribution to discourse begins to (re)shape the discourse itself. Extreme environments intensify the separation of discourse from experience because so few participants in the discourse have direct experience of these isolated locations.

There are consequences to substituting discourse for the direct experience of extreme environments. The more discourse builds on itself, the further it drifts from its subject. As each new article and author respond to works citing other works in an expanding feedback loop, noise is introduced to the system. The result is metadiscourse (discourse about 
discourse,) and possibly false discourse-false learning, misunderstanding, and the implementation of "worst practices" based on false discourse. This snowball effect can grow as false discourse influences beliefs, values and concepts about the environment. And because, "How we conceptualize the physical world is an important factor in determining how we treat nature," we may even begin to treat the environment differently. ${ }^{9}$ Treating it differently changes it, and if those changes result from false discourse, they may not be for the better.

\section{REPRESSION AND EXCLUSION}

Misinterpretation of extreme environments leading to false discourse may even represent a form of repression. Professor Celia Haig-Brown writes, "To paraphrase Foucault, as if in order to gain mastery over Indigenous thought, (materially speaking also over the people themselves, their lands and resources), it was necessary first to subjugate it at the level of language, control its free circulation in speech, expunge it from the things that were said, and extinguish the words that rendered it too visibly present."10 For example, misinterpretation of extreme environments and their architectural elements as primarily technological responses to climate may represent unintentional repression or subjugation of indigenous realities.

Metadiscourse which builds on itself disengaged from direct experience can distort perception of not just places, but people. The consequences can be not only a distorted view of minority people among the majority, but even a distorted self-image among minority people. These self-characterized negative stereotypes have been found to negatively affect academic performance. ${ }^{11}$ This could lead to a self-fulfilling prophecy in which majority discourse contributes to selfcharacterized negative stereotypes among minorities, which negatively affect their academic performance, leading to their further exclusion from academia and majority discourse.

In this way, discourse becomes an exclusionary "portal", to use James Paul Gee's term, through which indigenous and aboriginal scholars may struggle to pass. It could even be said that this portal is, in effect guarded by the peer review process. Peer-reviewed publication is the clearest badge of membership in any academic affinity space (to use another Gee term) defining subject areas in academic discourse. ${ }^{12}$ Yet peer review is conducted by those already within the affinity space and, as we have seen, the nature of discourse itself may discourage outside points of view despite the best intentions of its protagonists. If only the handful of people with a foot in both academic and minority affinity spaces can bring direct experience of extreme environments to academic discourse on those environments, this means there is almost no minority influence on the discourse shaping our impressions of extreme environments, or on the (re)definition of the discourse and affinity space themselves.

\section{WALKABOUT VERSUS TALKABOUT}

Deeply entwined with the theoretical contexts of knowledge exchange in extreme environments are the cultural contexts of that exchange. Material exchange between researchers and the cultures they study is far more restricted than it once was, mainly to reduce the exploitation of minority cultures and help them maintain ownership of their cultural artifacts. But exploitation may also occur when members of a minority culture produce artifacts with sacred or specific cultural meanings-Kachina dolls, for example-for mass consumption by tourists and outside consumers. Can the commercialization of behaviors such as the performance of the Hopi rain dance for tourists also constitute exploitation?

Cultural artifacts such as the Kachina doll and behaviors such as the Hopi rain dance are closely tied to the sacred, and their commercialization may be seen as acts of transgression. When behaviors go beyond representing the sacred to actually recreating it, what are the implications? Minority culture acts of "world making" such as the Aboriginal Australian Walkabout may serve as an example. As author Bruce Chatwin describes in his book, The Songlines,

"By singing the world into existence, the Ancestors had been poets in the original sense of poesis, meaning 'creation'. No Aboriginal could conceive that the created world was in any way imperfect. His religious life had a single aim: to keep the land the way it was and should be. The man who went 'Walkabout' was making a ritual journey. He trod in the footprints of his Ancestor. He sang the Ancestor's stanzas without changing a word or note-and so recreated the Creation."13

In this description, the Walkabout appears to go beyond recreation of the world to represent a continuous sustaining of it. References by Aboriginal Australians to the necessity of completing the Walkabout support this claim. ${ }^{14}$ This suggests that the Walkabout is a behavior that the Aboriginal world depends on for its survival, and the songlines are their architectural manifestation. In the same vein, the ancient Hawaiian creation saga presents the creation of the heiau [ital], or walled temple, as the first act of genesis, preceding even the creation of the earth and humankind. ${ }^{15}$ Since creation sagas in many ways reflect a culture's most foundational beliefs, does sharing architectural details of the heiau or songlines constitute transgression? If inhabitants of an extreme environment consider the entire environment sacred, rather than simply a vessel containing sacred places, does this place the entire environment off limits for study?

\section{SOCIAL AND FINANCIAL REMUNERATION}

Knowledge exchange in extreme environments also has repercussions for the social structures involved, and those structures may affect the exchange. Who, for example, do researchers engage in their search for local knowledge? What are the effects of the exchange on their informants? 
An increase or decrease in status is possible, within both the minority and majority culture. As a result of the exchange, informants may be perceived to migrate toward the majority culture, and researchers may be thought to move closer to the minority. In some cases, sharing certain minority knowledge may be seen as an act of transgression by informants.

For the researcher, presenting knowledge garnered from minority informants may increase or decrease status. Publication of new and valuable knowledge in one's field builds status. Conversely, publication seen as cultural appropriation may reduce the researcher's status, particularly among minority cultures. Professor Peter Nabakov, for instance, is the author of many influential books Native Americans. His book, Native American Architecture [ital title], offers many lessons in resilient design developed over hundreds of years by aboriginal builders. But Nabakov has also been confronted by Pueblo Indian representatives demanding to know what right he had to publish the Pueblo's sacred narratives in other texts. ${ }^{16}$ Their concerns appeared to be less with who benefits from capitalizing minority knowledge than who owns it; as former Governor of the Pueblo of Acoma, Fred S. Vallo Sr., explained, "We like to tell our own story. Let us do it." ${ }^{17}$

But commercial gain may also be a factor in knowledge exchange in extreme environments. Payments to informants, whether monetary or in other resources such as gifts, may change their status. Other parties, while not necessarily acting as informants, may also be perceived as gaining status or economic advantage. Leaders in the minority community may be involved in decision making related to a researcher's quest for information or educational activities. Property owners or managers may also interact. Knowledge consumers may also have a financial stake in the knowledge mining of extreme environments. These may include students, readers of publications, and professionals benefiting from new knowledge in resilient design.

In salaries for their teaching and royalties for their writing, researchers are paid for their knowledge. In many cases, they or their institutions pay for the knowledge they transform through their teaching and writing. Books are the most obvious example, as researchers or their institutions pay to purchase them. When the knowledge they transfer originates with minority cultures, should the knowledge providers be compensated in the same way the authors of the books are? The fact that knowledge seekers, bearers and consumers may value knowledge very differently further complicates relationships and transactions in the commercial context.

Because students, readers and professionals may pay for the knowledge provided by researchers and teachers who in turn may draw that knowledge from people in extreme environments, knowledge may be said to flow in the opposite direction from the money paid for it. This makes academia the nexus of theoretical and commercial exchange. Although commerce may play a role in the knowledge mining of extreme environments, its educational context sets it apart from the purely commercial world represented by the sale of cultural artifacts, mineral rights, and other resources. ${ }^{18}$ Researchers are, in theory at least, expected to place less emphasis on commercial gain than their counterparts in the business world. But knowledge is in many ways the primary capital in academia, and it is valued by its consumers, whether students, readers or professionals.

\section{INDIGENOUS ARCHITECTURE: WORLD-MAKING OR TECHNICAL SOLUTION?}

The knowledge possessed by minority cultures is not the only capital available to the researcher in extreme environments. The environment itself offers valuable lessons through the observation of plants, animals, climates, and ecosystem relationships. Inhabitants may also offer lessons through their behavioral adaptation to their harsh living conditions, making them subjects of study independent of the knowledge they possess. These environmental components and relationships are frequently held up as rich sources of architectural knowledge. Biomimicry, for example, is often touted as a key component of resilient design. Taken to the extreme, components of extreme environments may even be confiscated from their contexts, as in the case of biopiracy. Many extreme environments are in protected areas such as National Parks and Wilderness Areas. This places tight regulations on the impacts of research conducted there. Special permissions are required to remove environmental artifacts, interfere with wildlife, or even conduct extended observation. These regulations greatly reduce the direct impacts of mining extreme environments on wildlife, flora, soil and other physical aspects of the environment. However, attitudes toward the environment may be more easily affected.

Majority cultures are often accused of seeing the environment as a mere collection of capital resources such as fossil fuels, minerals and lumber. ${ }^{19}$ They may also see it as a collection of knowledge resources. When they do, it is tempting to polarize this attitude of exploitation with its perceived opposite: an attitude of stewardship held by indigenous or aboriginal minority cultures. And while this cliché has been hotly debated, the possibility of opposing attitudes toward nature is worth exploring. The commercialization of environmental resources in majority cultures is commonplace, as are the pantheistic attitudes of many minority cultures which hold the environment as something more than a collection of resources. Mountains provide an illustration of the difference. Many are revered as sacred places in minority cultures - the idea of climbing to their peaks nearly unthinkable. Enter the majority culture's explorers eager to conquer them, a not coincidental reflection of the relationship between the two cultures. 
When attitudes about the environment creep into the writings of a majority culture researcher, they may be perpetuated in the reader's mind. Proponents of social and cultural constructivism suggest that our perceptions of our environment are shaped more by these accumulated cultural representations than by the physical reality of that environment. ${ }^{20}$ But what are the implications of this "social construction of reality"? ${ }^{21}$ The Hawaiian heiau offers an example. A heiau, sometimes translated as temple, is a sacred site of worship. In Hawaiian lore, architecture came before the earth, animals or humans in creation, placing the heiau among the most sacred of artifacts. ${ }^{22}$ But seen from a technological perspective it is also a refined architectural response to its climate. To reduce the sacred heiau to a technological feat, however, is to reduce the religious beliefs surrounding it, and the people who hold them, to mere solutions to the problem of climate change. Can discourse on the architecture of extreme environments offer technological resilient design solutions and allow them to maintain their role as vehicles of indigenous world making?

\section{CONCLUSION}

Discourse on the architecture of extreme environments can embrace them as technological solutions to climate change while respecting their power in indigenous and aboriginal world making. But not if it excludes indigenous people. As we have seen, exclusion may not be due to any conscious efforts by participants in the discourse, but by the structure of discourse itself. The peer review system, for example, perpetuates the worldview of those already admitted. Can the affinity space of discourse on extreme environments be broadened to include more indigenous perspectives and participants? Metaphorically, the portal to the affinity space must be widened to allow participation by individuals with a foot in the indigenous world and another in the academic. This of course requires greater diversity in academia to ensure that indigenous scholars are included in the discourse. But it also requires greater direct experience of extreme environments by majority scholars to ensure that metadiscourse does not spiral out of control and disengage from direct experience. Perhaps most important is the further exploration of the liminal space between the indigenous environmental ontologies of world-making embodied in the Walkabout [ital]and the majority environmental ontologies of world-making embodied in metadiscursive talkabout [ital].

\section{ENDNOTES}

1 Ravindranath, N. H., and Jayant A. Sathaye. "Climate Change: Vulnerability, Impacts and Adaptation." 1 Intergovernmental Panel on Climate Change Working Group II AR5, March 31, 2014. doi:10.1007/0-306-47980-x_4. http:// www.cms.int/sites/default/files/document/IPCC_summary\%202014_optimized.pdf

2 Ellis, Ralph. "Dakota Pipeline: Army Corps Orders Protesters Out." CNN. November 28, 2016. http://www.cnn.com/2016/11/25/us/dakota-pipelineaccess-army-corps/index.html.

3 Haig-Brown, Celia. "Indigenous Thought, Appropriation, and Non-Aborigina People." Canadian Journal of Education 33, no. 4 (2010). http://www.jstor.org/ stable/canajeducrevucan.33.4.925.
4 Gulliford, Andrew. Sacred Objects and Sacred Places: Preserving Tribal Traditions. Boulder, CO: Univ. Press of Colorado, 2000.

5 Villela, Khristaan, “Controversy Erupts over Peter Nabokov's Publication of 'The Origin Myth of Acoma Pueblo,'” Santa Fe New Mexican, January 15, 2016. http://www.santafenewmexican.com/pasatiempo/columns/viajes_pintorescos/controversy-erupts-over-peter-nabokov-s-publication-of-the-origin/ article_1bcbe12b-b5c2-527e-93e9-1759fec994c5.html

6 Gee, James Paul. "What is Literacy?" In Negotiating Academic Literacies: Teaching and Learning Across Languages and Cultures. Ed. Vivian Zamel and Ruth Spack. Mahwah, NJ: Lawrence Erlbaum, 1998, 51-59.

7 Carroll, Joseph. "Poststructuralism, Cultural Constructivism and Evolutionary Biology, symplokē." Rhetoric and the Human Sciences 4, no. 1/2 (1996): 203-19.

8 Jackson, Doug. "Environments." Journal of Architectural Education. February 23, 2016. http://www.jaeonline.org/pages/environments\#/page1/

9 Cahn, Matthew, and Rory O'Brien. Thinking About the Environment. M.E. Sharpe, 1996.

10 Haig-Brown, Indigenous Thought, Appropriation, and Non-Aboriginal People, 932

11 Wertsch, James V. Voices of the Mind: A Sociocultural Approach to Mediated Action. Cambridge, MA: Harvard Univ. Press, 1991. p. 171

12 Gee, James Paul. Situated Language and Learning A Critique of Traditional Schooling. NY: Routledge, 2004.13.Chatwin, Bruce. The Songlines. London: Pan Books, 1988.

13 Ibid.

14 Kupihea, Moke. The Cry of the Huna: The Ancestral Voices of Hawaii. Rochester, VT: Inner Traditions, 2005. 3.

15 Villela, "Controversy Erupts over Peter Nabokov's Publication of 'The Origin Myth of Acoma Pueblo""

16 Ibid.

17 "Issues in Higher Education." AAUP. https://www.aaup.org/ issues-higher-education.

18 Jackson, Doug. "Environments." Journal of Architectural Education. February 23, 2016. http://www.jaeonline.org/pages/environments\#/page1/.

19 Hutchison, CB, Cultural Constructivism: The Confluence of Cognition, Knowledge Creation, Multiculturalism, and Teaching, 301-310 | Published online: 20 Nov 2006.

20 Berger, Peter L., and Thomas Luckmann. The Social Construction of Reality: A Treatise in the Sociology of Knowledge. London: Penguin Books, 1966.

21 Kupihea, 3. 